\title{
TRITIUM PROOF-OF-PRINCIPLE INJECTOR EXPERIMENT
}

\author{
P. W. FISHER, S. L. MILORA, S. K. COMBS \\ Oak Ridge National Laboratory* \\ Oak Ridge, TN 37831 , U.S.A. \\ $615-5 \uparrow 4-8051$
}

R. V. CARI,SON, D. O. COFFIN

Los Alamos National Laboratory

Los Alamos, NM 87545, U.S.A.

$505-667-3651$

\begin{abstract}
ABSTFACT
The Tritium Proof-sf-Principle (TPOP) pellet injector was designed and built by Oak Ridge Nalional Laboratory (ORNL) to evaluate the production and acceleration of tritium pellets for fueling future fusion reactors. The injector uses the pipe-gun concept to form pellets directly in a short liquid-helium-cooled section of the barrel. Pellets are accelerated by using highpressure hydrogen sipplied from a fast solenoid valve. $A$ versatile, tritium-compatible gas-handling system provides all of the functions needed to operate the gun, including feed gas pressure control and flow control, plus heliurn separacion and preparation of mixtıres. These systems are contained in a glovebr for secondary containment of tritium. Tritium experiments will be carried out at the Tritium Systems Test Assembly (TSTA) at Los Alamos National Laboratory (LANL).
\end{abstract}

\section{INTRODUCTION}

Injection of solid high-velocity pellets of hydrogen iscitopes has been shown to be an effective means for fueling fusion experiments. ${ }^{1-5}$ All previous work has involved either hydrogen or deuterium pellets. This work will explore the production and acceleration of tritium peilets. Although many, if not ali, of the available pellet injector design concepts could be used to produce tritium pellets, the simple pipe-gun concept was chosen for these initial tritium experiments. In a pipe gun, pellets are produced by freezing the tritium directly in a short liquid-helium-conled section of the barrel. ${ }^{6-B}$ This concept is ideal for these experiments because no excess tritium is required to produce pellets and because there aje no moving parts inside the gun.

Radioactive decay of tritium is accompanied by several phenomena, which could affect the way pellet injectors are designed and nperated. For instance, helium-3 $\left({ }^{3} \mathrm{He}\right)$ is the natural decay product of tritium, which grows at a rate of $0.015 \mathrm{~mol} \% /(\mathrm{day} \cdot \mathrm{mol} \mathrm{T})$. Souers ${ }^{9}$ reported that low concentrations of helium can block the cryopumping action of systems with dimensions similar tin the pipe gun. Souers further reported that the best.

"Resenrch sponsored by the Office of Fusion Energy, U.S. Department of Energy. under contract DE-A('05-840 R'1401 with Wartin Marietta Energy Systems, inc.
${ }^{3}$ He level that can be achieved with uranium hed purification is $0.12 \%$. For this work, levels of $0.001 \%$ may be required. It takes about $I \mathrm{~h}$ to reach this level in pure tritium. For these reasons, a cryogenic ${ }^{3}$ He separator has been included as an integral part of the TPOP gun. Other potential problems could arise from the decay heat and the effect of ${ }^{3} \mathrm{He}$ growth on thermal conductivity and strength of the solid pellet. Added to this is the requirement of tritium compatibility for all tritium-wetted parts of the gun and injection line. The importance of these various effects and their potential impact on pellet injector design and operation are being studied during the course of this program.

\section{SYSTEM DESCRIPTION}

Figure 1 shows the basic components of the TPOP experimental system. 'These include the gun, the fast valve, and two pellet diagnostic stations, which are basically the system under test. The glovebox, tritium manifolds, and spiral pump are all components needed for tritium work.

In the TPOP gun, molecular tritium is condensed into a solid pellet by using liquid helium as a refrigerant. Each shot requires approximately $175 \mathrm{Ci}(50$ torr. $L$ ) of tritium, corresponding to the tritium content of a $t-\mathrm{mm}$ diam by $4-\mathrm{mm}$-long pellet. High-pressure gas, generally hydrogen at $10 \mathrm{MPa}(1500 \mathrm{psi})$, is then used in accelerate the solid tritium pellet down the 1-m-Inng harrel of the gun. The total gas used for each shot will be $-160 \mathrm{~Pa} \cdot \mathrm{m}^{3}$ (typically 1200 torr.L). In a fusion reactor, the pellet would be shot throngh a vacuum system into the plasma. At TSTA, the pellet will be stopped and evaporated when it hits the blank fange after the second diagnostic station.

Figure 2 shows the major interface between the TSTA and TPOP systems. Tritium for the experiment is supplied from a product container (PC) in the 'TSTA load-in/!oad-out system (LIO). The tritium and hydrogen exhansted after a shot will be collected by the TSTA transfer pump system ('TP1) and stored in another P(' in the 1.10. Alowit 25 typical shots can be stored in a PC. During some later uperation of the TSTA process loup, the hydrogen/tritium mixtures will be separated. The TSTA process loop is nor expected to operate at the same time as TPOP; however, this mode of operation is not precluded. 


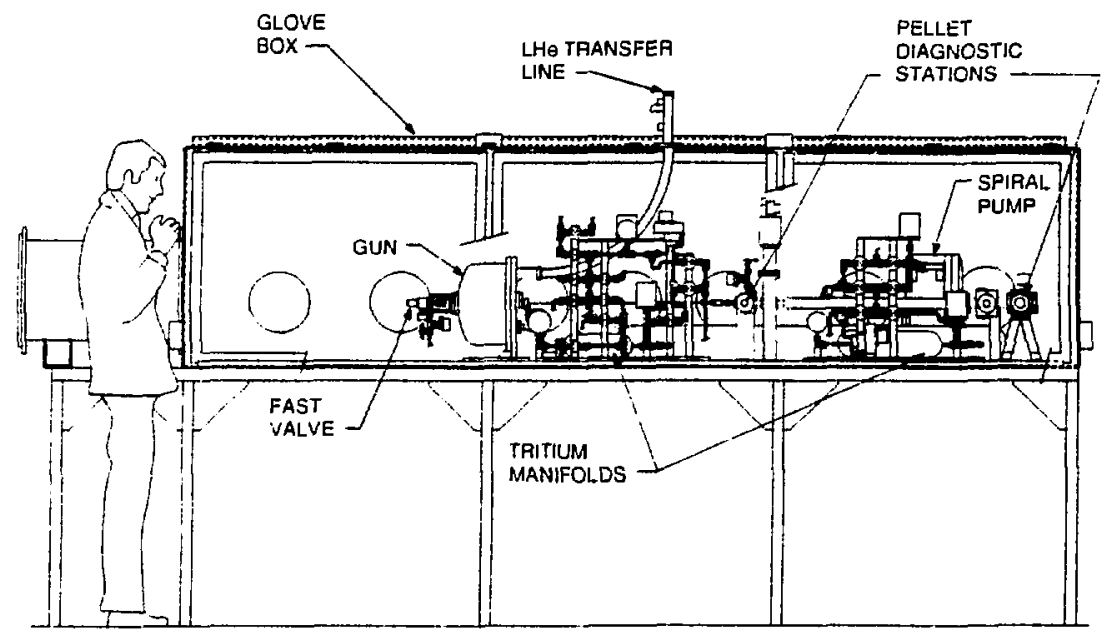

Fig. 1. TPOP experimental apparatus.

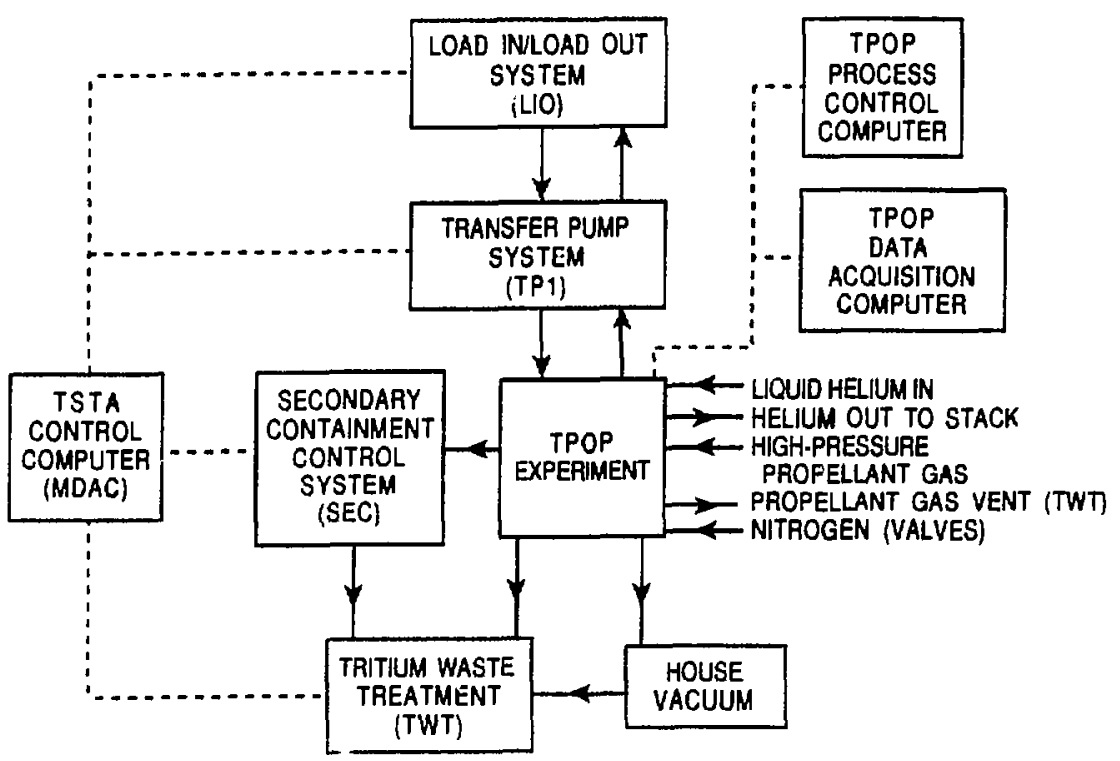

Fig. 2. Pellet injector/TSTA system interfaces.

\section{SECONDARY CONTAINMENT}

All of the tritium handling plumbing, the cryostat, and the gas injector valve for the experiment are contained inside the glovebox, as shown in Fig. 1. The glovebrox is a three-section box with a volume of approximately $3 \mathrm{~m}^{3}$. The glovebox atmosphere is altomatically purged to the tritium waste treatment system (TWT) when either high tritium levels $\left(>1 \mathrm{mCi} / \mathrm{m}^{3}\right)$ or high pressures are detected. Both tritium and hydrogen are used in the glovebox; therefore, nitrogen is
Itsed as the glnvehox atmosphere to prevent tire or explosive hazards if the system should develop a leak. I hydrogen detector is located in the glovebox to detect. leaks. The glovebox pressure controller is the standard TSTA controller. The tritium monitor (TM) for the glovebox is supplied by the TSTA. 'These are connerted to the TSTA computer and operated by the TM control program. The glovebox is also equipped with a pressure relief bubbler, which is connected to the stack duct.

The process lines connecting the TPOP glovebox to the TPl glovebox have secondary containment. The 
glovebox is equiวp with two quick disconnects so that a portable tritium monitor can be connected for tritium leak checking. With the exception of tritium lines, all gases enter the glovebox through check valves to prevent backflow contamination of the feed systems.

Liquid helium will be used inside the glovebox. The bubbler is sized to prevent overpressure of the glovebox if the cryogenic liquid is released into the box. Exhaust from the cryogenic systems is vented to the stack. Thus, the exhaust will be monitored for tritium before it is released to the environment.

\section{SYSTEM CONTROL AND INSTRUMENTATION}

The operation of values in the TPOP experiment can be controlled by either a local computer controller or manual switches (but nut both at the same time). Either of these systems can be used to sequence the valves for the firing of the pellet. Hard-wired safety interlocks prohibit introduction of high-pressure gas into the tritium plumbing, prevent firing into a closed vacuum line, and prevent loading tritium into the system if an exit value is open. Also, a single switch can be used to shut the experiment down. Process control data (including pressures, temperatures, flows, etc.) are logged on the process control computer. Data from the high-speed sensors in the pellet diagnostic stations are logged by a second computer.

Two small, solid-state television cameras are located in the glovebox for photographing the pellet after it is fired. The light source for the cameras is pulsed laser il. lumination brought into the box through fiber optics. The lasers are triggered with a velurity-independeni timing circuit tha! uses fiber optic light gates.

Most valves are pneumatically operated with nitro. gen. Valve positions are read by pressure switches in the valve operators, and the readings are transmit ted to the manual control panel and computer. All changes in valve position are logged, along with system alarms, by the process control computer, even if the valves are manually controlled. This log can be examined to determine what actions caused alarm conditions or failures. These data will also be used to track reliability of system components.

\section{SYSTEM PIPING}

Figure 3 shows a schematic diagram of the entire process system. The plumbing in the tritium system is stainless steel or copper. Joints are welded, brazed, Varian Conflat, or Cajon VCR. System components are all metal except for the valve stem tips (which are Vespel), quartz windows, and quartz optical fibers potted with Varian Torr Seal. The low-pressure piping is protected with aluminum bursting risks where it is possible for high-pressure hydrogen gas to be accidentally introduced or for frozen gas to be irapped between closed valves. The bursting disks for the process gas lines are exhausted to a 30-L volume (vacuum ballast, Fig, 3) located inside the glovebox. During operation, this volume is always open to the TP1 vacuum system.

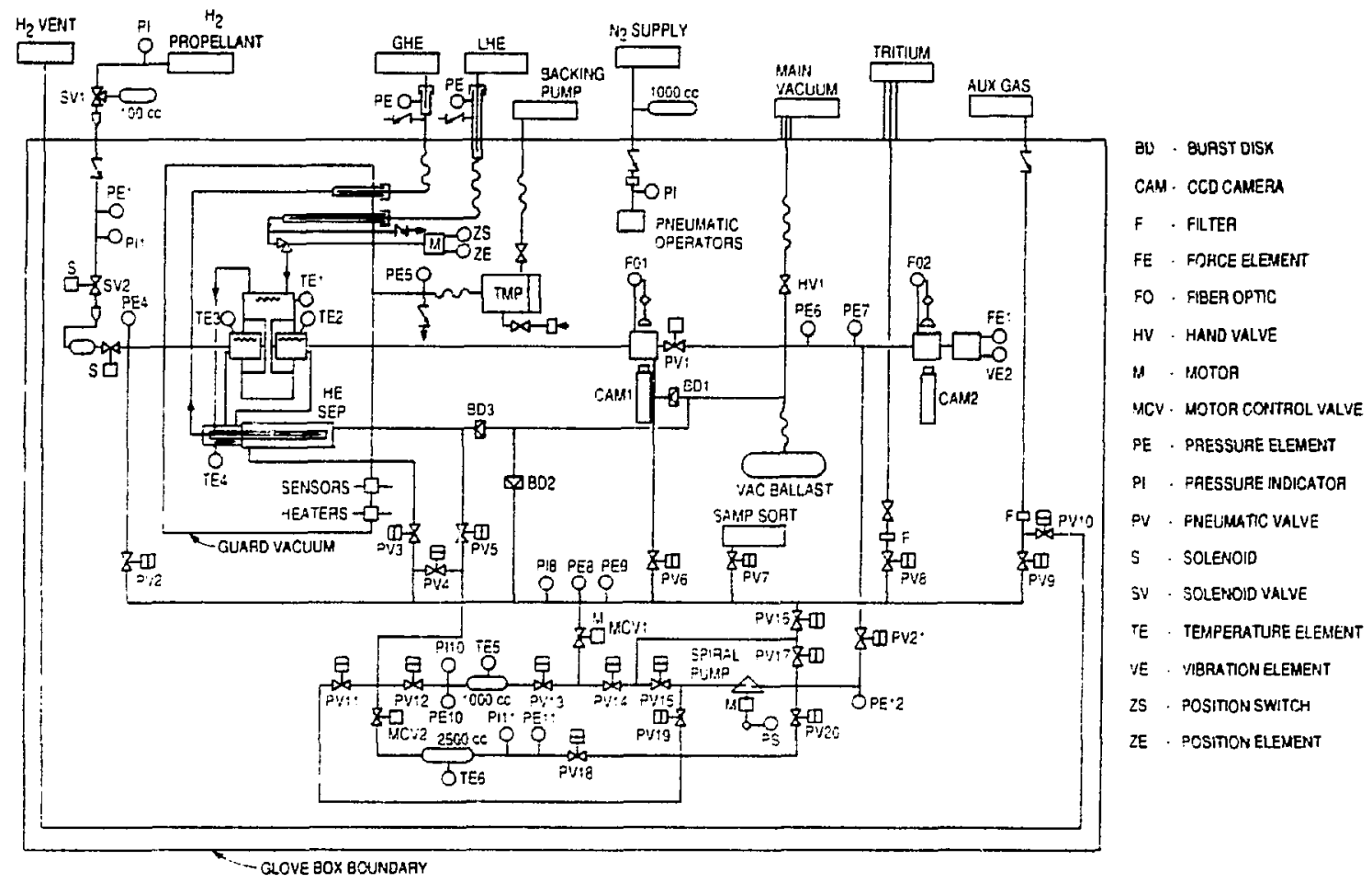

Fig. 3. TPUP system fow diagram. 
The system contains two volumes used to store and supply tritium to the exporiment. The $1000-\mathrm{cm}^{3}$ volume in Fig. 3 is used to measure tritium aliquots for feed to the gun, while the $2250-\mathrm{cm}^{3}$ volume is used as a bulk sturage reservoir. Motor control valves can be used to control pressure in both containers. To make mixtures, one container is filled with deuterium from the auxiliary gas line and the other is filled with tritium. The gas is then circulated in a loop for mixing.

A spiral-metal-diaphragm compound pump is used to transfer gas between different sections of the process system, to evacuate various parts of the system, and to circulate gas through the system. When necessary, it can be connected to the vacuum pumps in the TPl glovebox.

\section{PROPELLANT SYSTEM}

This system consists of the components necessary to provide the high-pressure gas that accelerates the solid tritium pellet down the gun barrel. Hydrogen will be used as the accelerating gas. Initial experiments will be done with hydrogen at 6.9 to $10 \mathrm{MPa}$ (1000 to $1500 \mathrm{psi}$ ); however. it may be necessary to use 34-MPa (5000-psi) gas in later experiments, so the system is designed for this pressure. Except for the fast-acting pulse valve, all romponents are commercial high-pressure components for which the lowest rated operating pressure is $36 \mathrm{MPa}$ (5200 psi). Gas will be supplied initiaily from a cylinder. it three-way valve (SVI) separates the hydrogen storage cylinder from the experirnent so that the volume of gas that can be released into the gloveloox is limited to approximately $100 \mathrm{~cm}^{3}$. Releasing this amount of gas into the box at $3-4 \mathrm{MPa}$ would cause a $23-\mathrm{Pa}(0.17-\mathrm{psi})$ pressure rise, not enough to cause a failure of the glovebox. even if all pressure control systems were to fail. Gasflow rate is limited by a snubber before the three-way valve and a snubber before the glovebux. The vent from the fast-deting valve will be sent oo the TWT, since this exhaust gas could contain a small quantity of tritium.

In initial tests, the propellant valve will be a fast solenoid valve described by Milora. ${ }^{10}$ This valve delivers $10 \mathrm{~cm}^{3}$ of gas to the breech of the gun in $<1 \mathrm{~ms}$. The gloveloox is designed to allow adequate space for addition of other driver systems at a later date.

\section{GUN SYSTEM}

The gun shown in Figs. 1 and 3 contains the cryogenic components of the pellet injector: the ${ }^{3} \mathrm{He}$ separator and the gun-block cryostat. 'The guard vaculuin consists of a stdinless steel vacuum jarket with jenetrations for instrumentation, liquid-helium refrigeration, process tritium lines, and a varuum line. All components in the guard vacuum are mounted from the front flange for ease of maintenance. The vacuunt is maintained by a turbo-molecular purnp, which is contained in the glovebox and exhausted through an external rough pump to the TWT. During normal operations, this vacuum space should not see tritium; however, failure of onc of several process lines could result in tritium in this spare.

Liquid helium is supplied from a dewar located next to the glovebox. Liquid helium transfer lines use screwed havonet fittings to ensure mechanical integrity and to inhibit inadvertent removal. A manual valye is located ontside the glovehox to shut off liquid helium flow in the event of a liquid helium leak in the glovebox. Screw caps with $O$-ring seals can be used to terminate lines for maintenance or during times of inactivity. A relief valve between the liquid helium valves inside and outside the glovebox relieves pressure in the event that both valyes are closed, trapping liquid helium. A gaseous helium purge is used to prevent backcondensation in the exhaust line during warming.

Helium-3 must be removed periodically from the tritium in the storage reservoir by using the ${ }^{3} \mathrm{He}$ separator. The separator is a copper countercurrent heat exchanger with liquid helium cooling and a large volume for tritium condensation and ${ }^{3} \mathrm{He}$ accumulation. The tritium $/{ }^{3} \mathrm{He}$ mixt t1re is cryopumped into the ${ }^{3} \mathrm{He}$ separator at less than $12 \mathrm{~K}$. At this temperature, the tritium will solidify and the ${ }^{3} \mathrm{He}$ will remain as a gas. The ${ }^{3} \mathrm{He}$ is evacuated from the separator and disposed of through the TWT. The tritium is then returned to the storage reserroir by warming the separator.

The gun is simply a 4-mm-ID by $0.41-\mathrm{mm}$ wall thickness stainless steel tube soldered into a 3-mm-thick copper insert in the gun block. The temperature of the liquid-helium-cooled gun block is controlled with heaters. If necessary, small cryostats can be clamperl on the barrel on both sides of the gun block to control pellet length. Tritium can be admitted to the vessel from either end, separately or simultaneously. After the pellet is formed, the gun is isolated from the tritium source and high-pressure gas is admitted to the gun to accelerate the pellet down the $1-\mathrm{m}$-long stainless steel gun barrel. The 30-I, yacuum ballast tank is connected to the pellet injection line to keep the pressure below 25 torr during a shot. All of the gas from the shot is pumped away by the TPI vacuum system.

\section{SYSTEM STATUS}

The system was fabricated, made fully operational, and tested at ORNL prior to installation at TSTA. At ORNL, nearly 800 pellets of hydrogen and deuterium were produced. Velocities as high as $1790 \mathrm{~m} / \mathrm{s}$ were achieved with $4-\mathrm{mm}$ by $4-\mathrm{mm}$ deuterium pellets using the standard propellant valve. These results indicate that the system should be capable of producing 1500 . $\mathrm{m} / \mathrm{s}$ tritium pellets. The system is now installed and operating with tritium at TSTA.

\section{REFERENCES}

1. S. I. MILORA et al., "Pellet Injection into PDX Diverted Plasmas," Nucl. Fusion 22, 1263 (1982).

2. M. GREFNWALD et ai., "Energy Confinement of High-Density Pellet-Fueled Plasmas in the Alrator (C Tokamak," Phys. Rev. Lett. 53, 352 (1984).

3. S. SENGOKO et al., "Improvement of Energy ('on finement Time by Continuons Pellet Fueling in BeamHeated Doublet III Limiter Discharges." .Vurl. Fusion 25, 1475 (1985).

1. S. L. MILORA et al.. "Confinement of High-Density Pellet-Fueled Discharge in T'FT'R.," Plasma Phys. ('ontrolled Fusion 28, 1.435) (1986). 
5. A. GONDHALEKAR et al., "Pellet Fueling of JET Plasma During Ohmic, ICRF, and NBI Heating," Proc. Itth Int. Conf. Plasma Physics and Controlled Nuclear Fusion Research, Kyoto, Japan, November 1986, Vol. 3, p. $45 \bar{T}$, International Atomic Energy Agency, Vienna (1987).

6. J. LAFFERANDERIE et al., "Experimental Test of 6-mm Diameter $\mathrm{D}_{2}$ Pellets Produced by In-Situ Condensation," in Proc. 14th Symposium on Fusion Technology, Avignon, France, 1986, p. 1367, Pergamon Press, Oxford (1986).

†. S. K. COMBS, S. L. MILORA, and C. R. FOUST, "Simple Pipe Giun for Hydrogen Pellet Injection," Rev. Sci. Instrum. 57, 2636 (1986).
8. H. 3ORENSEN et al., "Simplified Pipe Gun," Rev. Sci. Instrum. 58, 2336 (1987).

9. P. C. SAUERS el al., "Anomalous Vapor Pressure Over Liquid Deulerium Tritium," Cryogenics 22, 45 (1982).

10. S. L. MILORA, S. K. COMBS, and C. R. FOUST, "Fast Opening Magnetic Valve for High-Pressure Gis Injection and Applications to Hydrogen Pellet Fueling Systems," Ilev. Sci. Instrum. 57, 2356 (1986).

\section{DISCLAIMER}

This report was prepared as an account of work sponsored by an agency of the United States Government. Neither the United States Government nor any agency thereof, not any of their employees, makes any warranty, express or implied, or assumes any legal liability or responsibility for the accuracy, completeness, or usefulness of any information, apparatus, product, or process disclosed, or represents that its use would not infringe privately owned rights. Reference herein to any specific commercial product, process, or service by trade name, trademark, manufacturer, or otherwise does not necessarily constitute or imply its endorsement, recommendation, or favoring by the United States Government or any agency thereof. The views and opinions of authors expressed herein do not necessarily state or reflect those of the United States Government or any agency thereof. 